\title{
Osteometrical Study of Sacrum and Coccygeal Vertebrae in a Marsh Crocodile (Crocodylus palustris)
}

\author{
T. Mayakkannan ${ }^{1 *}$, T.A. Kannan ${ }^{2}$, Geetha Ramesh $^{1}$ and S. Venkatesan ${ }^{3}$ \\ ${ }^{1}$ Department of Veterinary Anatomy, Madras Veterinary College, Tamil Nadu Veterinary and \\ Animal Sciences University, Chennai-600 007, Tamil Nadu, India \\ ${ }^{2}$ School of Veterinary Medicine, The University of West Indies, Trinidad and Tobaco \\ ${ }^{3}$ Centre for Stem Cell Research and Regenerative Medicine, Madras Veterinary College, \\ Tamil Nadu Veterinary and Animal Sciences University, Chennai-600 007, Tamil Nadu, India \\ *Corresponding author
}

\begin{tabular}{|c|c|}
\hline & A B S T R A C T \\
\hline & \multirow{6}{*}{$\begin{array}{l}\text { The Marsh crocodile (Crocodylus palustris) was one of the three crocodilians species } \\
\text { found in India. The present study designed to document the Osteometrical details of sacral } \\
\text { and coccygeal vertebrae of Marsh crocodile. The bones were prepared from a carcass } \\
\text { brought for post-mortem examination. The sacrum and coccygeal vertebrae were } 2 \text { and } 26 \\
\text { in number respectively. Both the vertebrae were concave on the anterior side and convex } \\
\text { on the posterior side of the centrum (Procoelous type). The two sacral vertebrae were } \\
\text { separate and typical consisting of a centrum, neural arch and other processes. The } \\
\text { expansive ribs of sacral vertebrae formed a robust structure which connects the vertebral } \\
\text { column to the pelvic girdle. Among } 26 \text { Coccygeal, first } 16 \text { were typical and the remaining } \\
\text { were atypical vertebrae. Prominent chevron bones were observed up to } 11^{\text {th }} \text { coccygeal } \\
\text { vertebrae attaching to the postero-ventral edges of the centrum. Though the sample size } \\
\text { was insufficient, the results of this study provided basic details of sacral and coccygeal } \\
\text { vertebrae and helps in understanding the role of axial column in crocodilian locomotion } \\
\text { which was functionally different from mammals, even during analogous gaits. }\end{array}$} \\
\hline Keywords & \\
\hline & \\
\hline Article & \\
\hline $\begin{array}{l}\text { Accepted } \\
10 \text { Septer } \\
\text { Available } \\
10 \text { Octob }\end{array}$ & \\
\hline & \\
\hline
\end{tabular}

\section{Introduction}

The Marsh crocodile (Crocodylus palustris) is one of the three crocodilians found in India, the others being Gharial and Saltwater crocodile (Hiremath, 2003). Marsh is a medium-sized crocodile (maximum length of about 4-5 $\mathrm{m}$ ), and has the broadest snout among the member of the genus Crocodylus. In India, Crocodylus palustris has adapted well to reservoirs, irrigation canals and man- made ponds and even in coastal saltwater lagoons and estuaries (Da Silva and Lenin, 2010).

The lineage leading to has under gone. A dramatic evolutionary change takes place in morphology, ecology and locomotion over the past 200 years among the members of modern Crocodylia. The modern crocodylians showed a wide range of terrestrial locomotive behaviours, including asymmetrical gaits as in 
mammals. The key to these diverse abilities lie in the axial skeleton. Being semi aquatic species, vertebral column in a marsh is architectured in such way that they swim and can also walk on their short, stubby legs. Since, the vertebral column is the essential part of locomotor apparatus; its morphology can provide essential clues about locomotion in marsh (Molnar et al., 2015).

The regional differentiation in the crocodilian vertebral column is not as pronounced as seen in mammals (Shapiro, 2007; Pierce et al., 2011; Molnar et al., 2015). The primary function of sacrum in crocodiles is to provide body support and mobilization during terrestrial locomotion along with its hind limb. Whereas, in the coccygeal bones helps mainly in swimming (Frey and Salisbury, 2001). The understanding of the locomotor and aquatic adaptation in marsh crocodiles relies on the changes in the vertebral column especially sacrum and coccygeal vertebrae. The published work on the morphological and morphometrical studies on the marsh crocodile is scanty. Hence, the present study was aimed to document the morphological and morphometric changes in sacrum and coccygeal vertebrae in a marsh crocodile.

\section{Materials and Methods}

The materials for the present study were collected from a 19 year-old female Marsh crocodile carcass from Guindy National Park, Chennai, Tamil Nadu brought for necropsy to the Department of Veterinary Pathology, Madras Veterinary College, Chennai. Sacrococcygeal region of the carcass was skinned and defleshed to the extent possible. After evisceration, the remaining carcass was buried at 4 feet depth in ground as per Onwuama et al., (2012). The macerated bones were removed after about eleven months. The bones were cleaned properly with washing powder in lukewarm water. The cleaned bones were allowed to dry in hot sun and used for the study.

Processed sacral and coccygeal vertebrae were utilised for morphometric studies by using measuring tape and vernier caliper. Width and length of the centrum (WC and LC), length and width of the Pre-Zygapophyses (PrzL and PrzW) and Post-Zygapophyses (PozL and PozW), height and width of the neural spine (NSH and NSW), vertical and transverse diameters of vertebral ring and length and width of transverse processes (TPL and TPW) were estimated and the values were given in Table 1, 2 and 3 .

\section{Results and Discussion}

\section{Sacrum}

In the present study, the sacrum was made-up of two unfused sacral vertebrae as reported by Johnston et al., (2014). Both the vertebrae were typical vertebrae, which consisted of an axial cylindrical piece called centrum, to which different processes were attached (Fig. 1). The number of sacral vertebrae varies from animal to animal. Amphibians have a single sacral vertebra and mammals have three or more.

The centrum of the $S_{1}$ showed anterior concavity and posterior convexity (Procoelous type). This arrangement is hypothysed to be more resistant to fracture and provide better stabilization for inter central articulation (Fronimos et al., 2016).

The centrum provides strength to vertebra and connects one vertebra to another (Girish Chandra, 2011). The centrum was narrow at its middle and expanded on either end in both vertebrae. Second sacral vertebra was slightly longer than the first (Table 1). Whereas, in $\mathrm{S}_{2}$, both the ends were found to be concave (Fig. 2). 
The neural arch and neural spine were attached on the dorsal side of the centrum to enclose the neural ring which protected the spinal cord. The neural arch was made up of horizontal lamina and vertical pedicle (Fig. 3).

The neural spine was surmounted over the neural arch and well developed in $S_{1}$ (Fig. $1 b$ and 1c). The height and width of the neural spine decreased in $S_{2}$ (Table 1). The neural spine was straight in both the vertebra (Molnar et al., 2014). The vertical and transverse diameters of the vertebral ring were lesser in $S_{2}$ when compared to $S_{1}$ (Table 1).

The ventral spinous process or Hypapophyses was absent in sacrum of Mugger (Fig. 2). The length and width of pre and postzygapophyses were lesser in $\mathrm{S}_{2}$ (Table 1).
The transverse process of $S_{1}$ was narrow, projected from the dorso-lateral aspect of the centrum were narrow and straight (Fig. 3). Whereas, in $S_{2}$ transverse process were projected backward and upward. Its width was more than the length (Table 1). The articular facets of the transverse process of the sacrum articulate with the hip bones to form the pelvis. The sacrum was a very strong bone that supports the weight of the upper body as it is spread across the pelvis and into the legs.

\section{Coccygeal vertebrae}

Coccygeal vertebrae were 26 in number in the present study (Fig. 4 and 5). Of which, first 14 were typical vertebrae and the remaining were atypical vertebrae as per Swinton, (1937) and Buscalioni and Sanz (1990).

Table.1 Morphometric details of Sacral Vertebrae (all the values were in Centimeters)

\begin{tabular}{|c|c|c|}
\hline Parameters & S1 & S2 \\
\hline \multicolumn{3}{|l|}{ Body - Width(WC) } \\
\hline Anterior & 4.2 & 3.2 \\
\hline Middle & 3.2 & 3.2 \\
\hline Posterior & 3.3 & 4.0 \\
\hline Centrum - Length(LC) & 3.4 & 3.5 \\
\hline \multicolumn{3}{|l|}{ Neural spine (NS) } \\
\hline Height (NSH) & 3.9 & 3.0 \\
\hline Width (NSW) & 3.0 & 2.7 \\
\hline \multicolumn{3}{|c|}{ Vertebral ring- Vertical diameter } \\
\hline Cranial & 1.7 & 1.6 \\
\hline Caudal & 1.7 & 1.4 \\
\hline \multicolumn{3}{|c|}{ Vertebral ring- Transverse diameter } \\
\hline Cranial & 1.9 & 1.9 \\
\hline Caudal & 1.8 & 1.6 \\
\hline \multicolumn{3}{|l|}{ Pre-Zygapophyses (PrZ) } \\
\hline Length (PrzL) & 2.1 & 1.3 \\
\hline Width (PrzW) & 1.3 & 0.7 \\
\hline \multicolumn{3}{|l|}{ Post-Zygapophyses (PoZ) } \\
\hline Length (PozL) & 1.2 & 1.6 \\
\hline Width (PozW) & 0.8 & 1.0 \\
\hline \multicolumn{3}{|l|}{ Transverse process (TP) } \\
\hline Length (TPL) & 5.5 & 3.0 \\
\hline Width (TPW) & 3.0 & 5.0 \\
\hline
\end{tabular}


Table.2 Morphometric details of Typical Coccygeal Vertebrae (all the values were in Centimeters)

\begin{tabular}{|c|c|c|c|c|c|c|c|c|c|c|c|c|c|c|}
\hline Parameters & $\mathrm{Cy}_{1}$ & $\mathrm{Cy}_{2}$ & $\mathrm{Cy}_{3}$ & $\mathrm{Cy}_{4}$ & $\mathbf{C y}_{5}$ & $\mathrm{Cy}_{6}$ & $\mathrm{Cy}_{7}$ & $\mathrm{Cy}_{8}$ & $\mathrm{Cy}_{9}$ & $\mathbf{C y}_{10}$ & $\mathrm{Cy}_{11}$ & $\mathrm{Cy}_{12}$ & $\mathrm{Cy}_{13}$ & $\mathrm{Cy}_{14}$ \\
\hline \multicolumn{15}{|c|}{ Centrum-Width(WC) } \\
\hline Anterior & 3.1 & 3.0 & 2.9 & 2.8 & 2.6 & 2.5 & 2.4 & 2.4 & 2.3 & 2.3 & 2.3 & 2.2 & 2.2 & 2.0 \\
\hline Middle & 2.4 & 2.3 & 2.2 & 2.1 & 2.0 & 2.0 & 1.9 & 1.7 & 1.7 & 1.6 & 1.5 & 1.5 & 1.4 & 1.4 \\
\hline Posterior & 3.1 & 3.0 & 2.9 & 2.8 & 2.6 & 2.5 & 2.4 & 2.4 & 2.3 & 2.3 & 2.3 & 2.2 & 2.2 & 2.0 \\
\hline Length(LC) & 4.0 & 4.1 & 4.2 & 4.2 & 4.2 & 4.4 & 4.4 & 4.5 & 4.5 & 4.5 & 4.5 & 4.5 & 4.7 & 4.8 \\
\hline \multicolumn{15}{|c|}{ Neural spine(NS) } \\
\hline Height(NSH) & 3.9 & 4.0 & 4.1 & 4.2 & 4.2 & 4.3 & 4.3 & 4.4 & 4.5 & 4.6 & 4.7 & 4.9 & 5.0 & 5.5 \\
\hline Width(NSW) & 2.0 & 1.9 & 1.9 & 1.7 & 1.7 & 1.7 & 1.5 & 1.4 & 1.3 & 1.3 & 1.3 & 1.2 & 1.1 & 1.0 \\
\hline \multicolumn{15}{|c|}{ Vertebral ring -Vertical diameter } \\
\hline Cranial & 1.2 & 1.1 & 1.1 & 1.0 & 1.0 & 1.0 & 1.0 & 0.9 & 0.9 & 0.9 & 0.9 & 0.8 & 0.8 & 0.8 \\
\hline Caudal & 1.2 & 1.1 & 1.1 & 1.0 & 1.0 & 1.0 & 1.0 & 0.9 & 0.9 & 0.9 & 0.9 & 0.8 & 0.8 & 0.8 \\
\hline \multicolumn{15}{|c|}{ Vertebral ring - Transverse diameter } \\
\hline Cranial & 1.3 & 1.2 & 1.2 & 1.1 & 1.1 & 1.1 & 1.1 & 1.0 & 1.0 & 1.0 & 1.0 & 1.0 & 1.0 & 1.0 \\
\hline Caudal & 1.3 & 1.2 & 1.2 & 1.1 & 1.1 & 1.1 & 1.1 & 1.0 & 1.0 & 1.0 & 1.0 & 0.9 & 0.9 & 0.9 \\
\hline \multicolumn{15}{|c|}{ Pre-Zygapophyses (PrZ) } \\
\hline Length(PrzL) & 1.5 & 1.4 & 1.3 & 1.2 & 1.2 & 1.2 & 1.1 & 1.1 & 1.0 & 1.0 & 1.0 & 0.9 & 0.9 & 0.8 \\
\hline Width(PrzW) & 1.2 & 1.1 & 1.0 & 0.9 & 0.9 & 0.8 & 0.8 & 0.8 & 0.7 & 0.7 & 0.7 & 0.7 & 0.7 & 0.6 \\
\hline \multicolumn{15}{|c|}{ Post- Zygapophyses (PoZ) } \\
\hline Length(PozL) & 1.3 & 1.2 & 1.1 & 1.0 & 1.0 & 1.0 & 0.9 & 0.9 & 0.8 & 0.8 & 0.8 & 0.8 & 0.8 & 0.7 \\
\hline Width(PozW) & 1.2 & 1.1 & 1.0 & 0.9 & 0.9 & 0.9 & 0.8 & 0.8 & 0.7 & 0.7 & 0.7 & 0.7 & 0.7 & 0.6 \\
\hline \multicolumn{15}{|c|}{ Transverse process (TP) } \\
\hline Length (TPL) & 4.1 & 4.0 & 3.9 & 3.8 & 3.6 & 3.4 & 3.4 & 3.2 & 3.0 & 2.7 & 2.5 & 2.5 & 2.5 & 1.6 \\
\hline Width (TPW) & 1.6 & 1.5 & 1.4 & 1.3 & 1.3 & 1.2 & 1.2 & 1.0 & 0.8 & 0.7 & 0.6 & 0.6 & 0.6 & 0.4 \\
\hline
\end{tabular}

Table.3 Morphometric details of Atypical Coccygeal Vertebrae (all the values were in Centimeters)

\begin{tabular}{|c|c|c|c|c|c|c|c|c|c|c|c|c|}
\hline Parameters & $\mathrm{Cy}_{15}$ & $\mathrm{Cy}_{16}$ & $\mathrm{Cy}_{17}$ & $\mathrm{Cy}_{18}$ & $\mathrm{Cy}_{19}$ & $\mathrm{Cy}_{20}$ & $\mathrm{Cy}_{21}$ & $\mathrm{Cy}_{22}$ & $\mathrm{Cy}_{23}$ & $\mathrm{Cy}_{24}$ & $\mathrm{Cy}_{25}$ & $\mathrm{Cy}_{26}$ \\
\hline \multicolumn{13}{|c|}{ Centrum-Width (WC) } \\
\hline Anterior & 1.9 & 1.9 & 1.8 & 1.8 & 1.7 & 1.7 & 1.7 & 1.6 & 1.4 & 1.2 & 1.1 & 1.1 \\
\hline Middle & 1.1 & 1.1 & 1.0 & 1.0 & 0.8 & 0.8 & 0.8 & 0.7 & 0.5 & 0.5 & 0.5 & 0.4 \\
\hline Posterior & 1.9 & 1.9 & 1.8 & 1.8 & 1.7 & 1.7 & 1.7 & 1.6 & 1.3 & 1.2 & 1.1 & 1.0 \\
\hline Length (LC) & 4.6 & 4.6 & 4.5 & 4.4 & 4.3 & 4.2 & 4.2 & 4.1 & 3.9 & 3.8 & 3.1 & 3.0 \\
\hline \multicolumn{13}{|c|}{ Neural spine (NS) } \\
\hline Height (NSH) & 5.7 & 6.0 & 6.3 & 6.0 & 5.8 & 5.5 & 5.2 & 4.8 & 4.0 & 3.6 & 3.1 & 0.29 \\
\hline Width (NSW) & 1.0 & 0.8 & 0.8 & 0.8 & 0.7 & 0.6 & 0.6 & 0.6 & 0.5 & 0.4 & 0.3 & 0.29 \\
\hline \multicolumn{13}{|c|}{ Vertebral ring - Vertical diameter } \\
\hline Cranial & 0.7 & 0.7 & 0.7 & 0.7 & 0.6 & 0.6 & 0.6 & 0.5 & 0.4 & 0.4 & 0.4 & 0.3 \\
\hline Caudal & 0.7 & 0.7 & 0.7 & 0.7 & 0.6 & 0.6 & 0.6 & 0.6 & 0.5 & 0.5 & 0.4 & 0.3 \\
\hline \multicolumn{13}{|c|}{ Vertebral ring - Transverse diameter } \\
\hline Cranial & 0.9 & 0.9 & 0.9 & 0.9 & 0.8 & 0.8 & 0.8 & 0.7 & 0.7 & 0.6 & 0.5 & 0.4 \\
\hline Caudal & 0.8 & 0.8 & 0.8 & 0.8 & 0.7 & 0.7 & 0.7 & 0.6 & 0.6 & 0.6 & 0.5 & 0.4 \\
\hline \multicolumn{13}{|c|}{ Pre-Zygapophyses (PrZ) } \\
\hline Length (PrzL) & 0.7 & 0.7 & 0.6 & 0.6 & 0.5 & 0.5 & 0.5 & 0.4 & 0.4 & 0.4 & 0.4 & 0.4 \\
\hline Width (PrzW) & 0.5 & 0.5 & 0.4 & 0.4 & 0.3 & 0.3 & 0.3 & 0.2 & 0.2 & 0.2 & 0.2 & 0.2 \\
\hline \multicolumn{13}{|c|}{ Post-Zygapophyses (PoZ) } \\
\hline Length (PozL) & 0.6 & 0.6 & 0.5 & 0.5 & 0.4 & 0.4 & 0.4 & 0.3 & 0.3 & 0.3 & 0.3 & 0.3 \\
\hline Width (PozW) & 0.5 & 0.5 & 0.4 & 0.4 & 0.3 & 0.3 & 0.3 & 0.2 & 0.2 & 0.2 & 0.2 & 0.2 \\
\hline
\end{tabular}


Fig.1 Panoramic view (dorsal) of $S_{1}$ to $S_{2}$

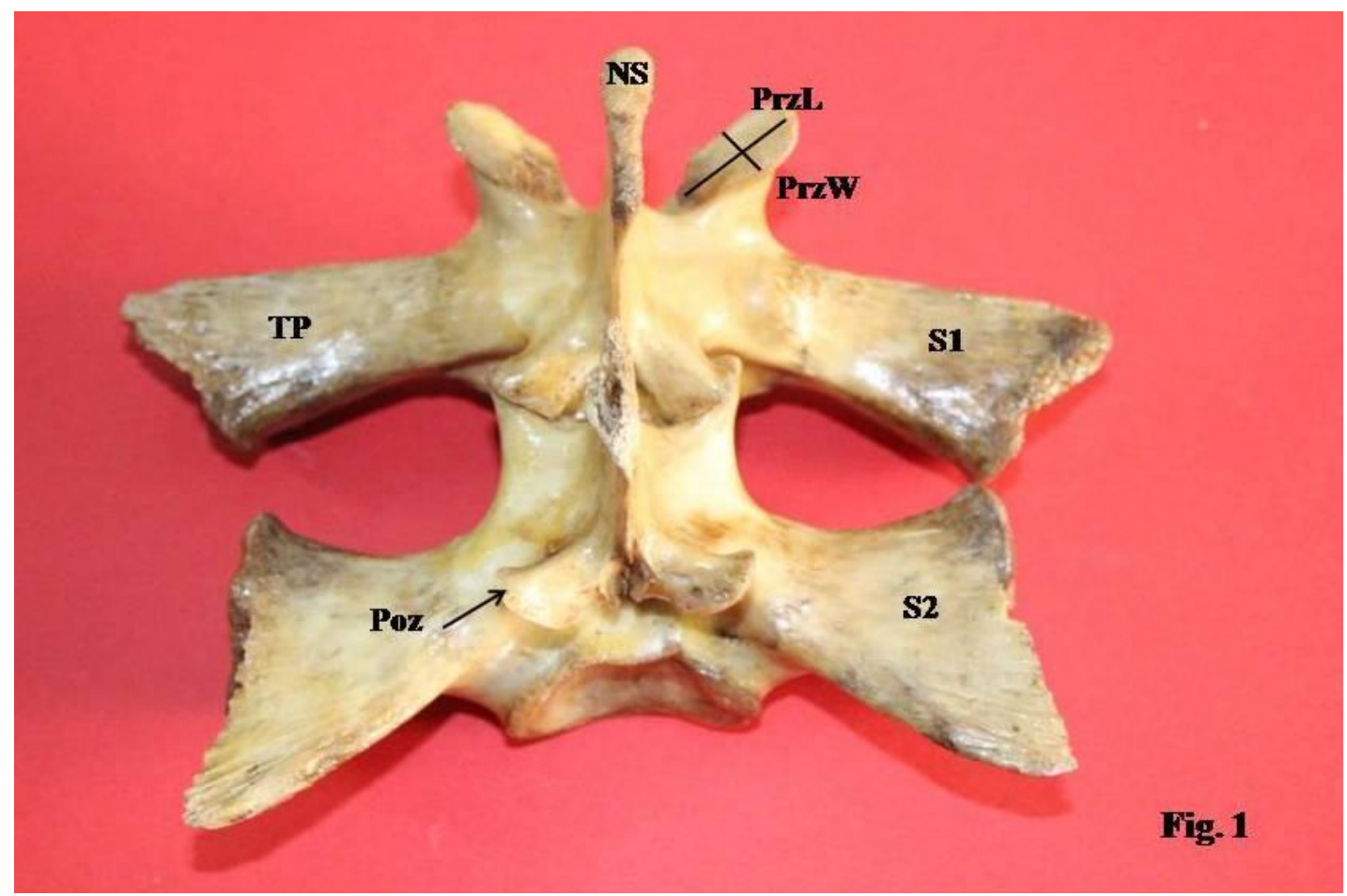

NS-Neural Spine, TP-Transverse Process, Poz-Post-zygapophyses, PrzL-Pre-zygapophyses Length and PrzW-Prezygapophyses Width

Fig.2 Ventral view of $S_{2}$ vertebra showing biconcavity of centrum (Blue arrow)

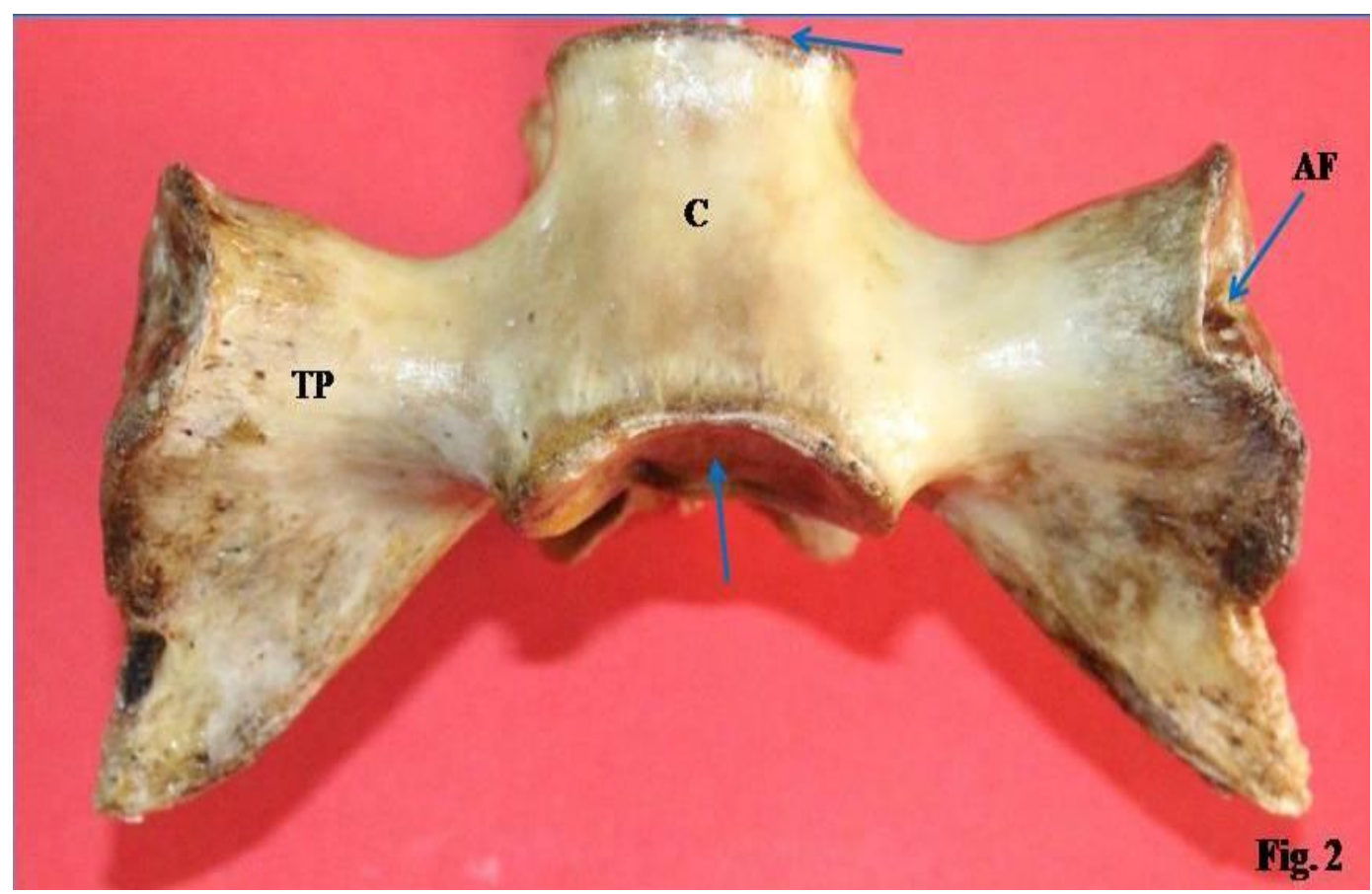

AF-Articular Facets, C-Centrum and TP-Transverse Process 
Fig.3 Cranial view of $S_{1}$

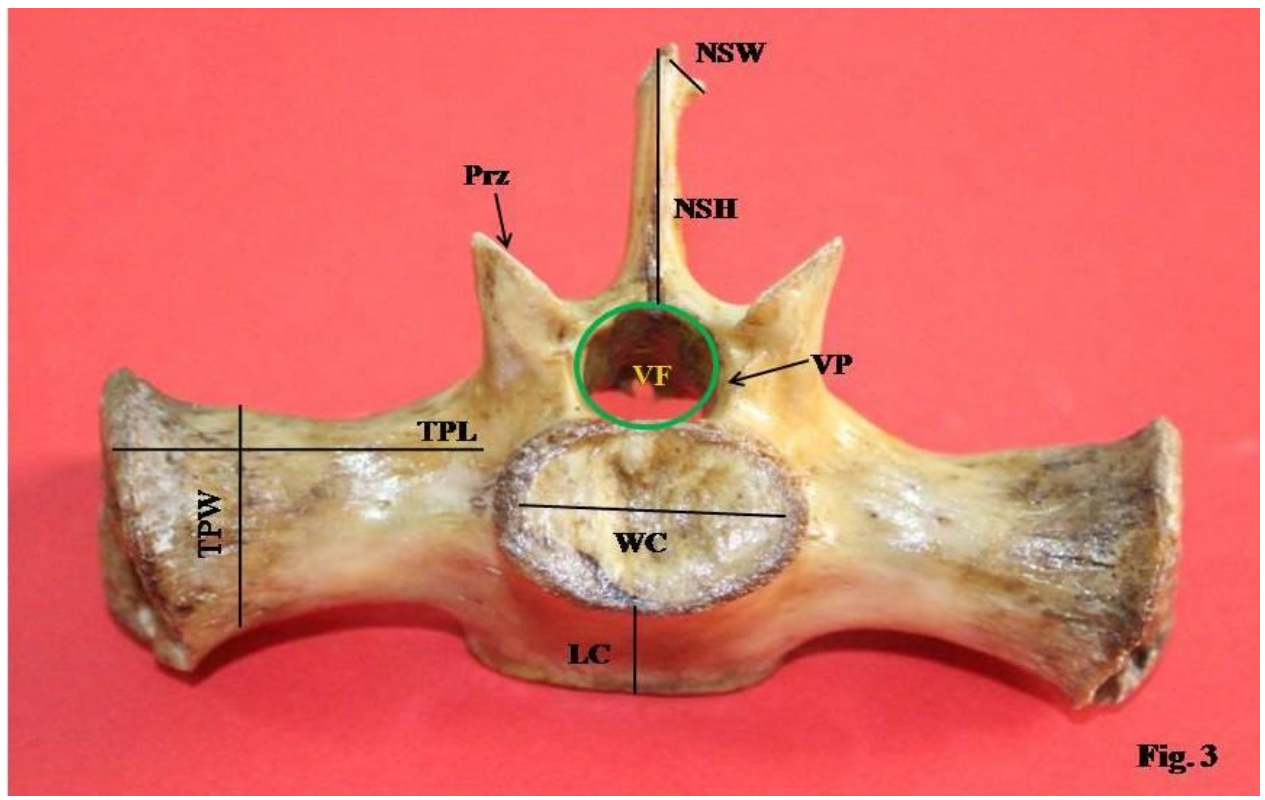

NSW- Neural Spine Width, NSH- Neural Spine Height, Prz-Pre-zygapophyses, VF- Vertebral Foramen, VPVertical Pedicle, WC-Centrum Width, LC-Centrum Length, TPW- Transverse Process Width and TPL-Transverse Process Length

Fig.4 Panoramic view of $\mathrm{Cy}_{1}$ to $\mathrm{Cy}_{14}$

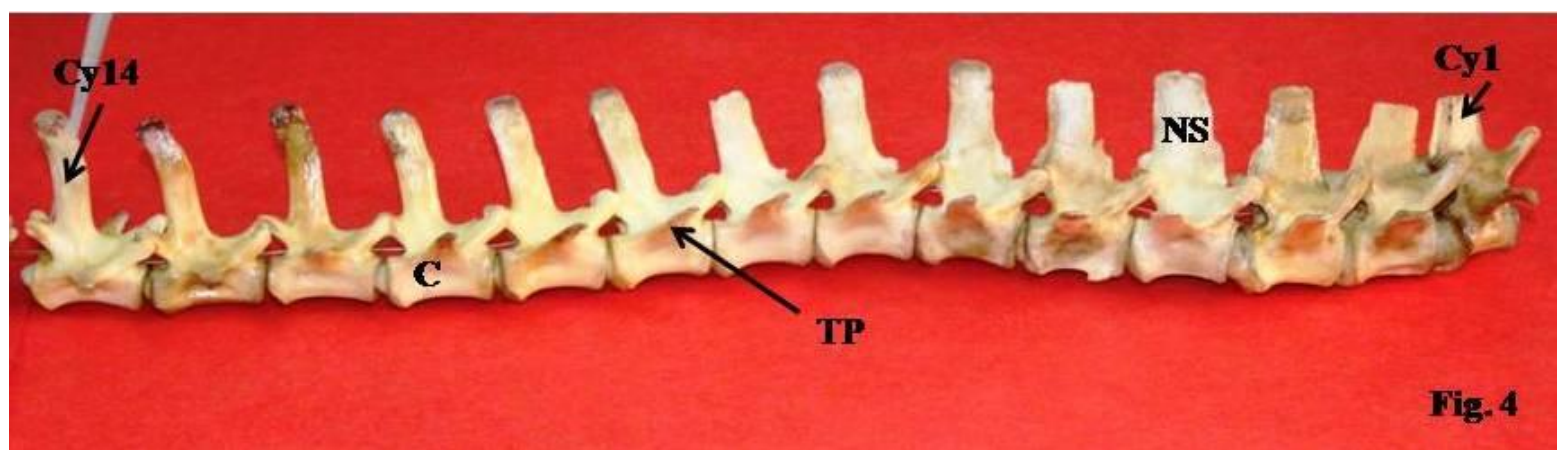

NS-Neural Spine and TP-Transverse Process

Fig.5 Panoramic view of $\mathrm{Cy}_{15}$ to $\mathrm{Cy}_{26}$ NS-Neural Spine

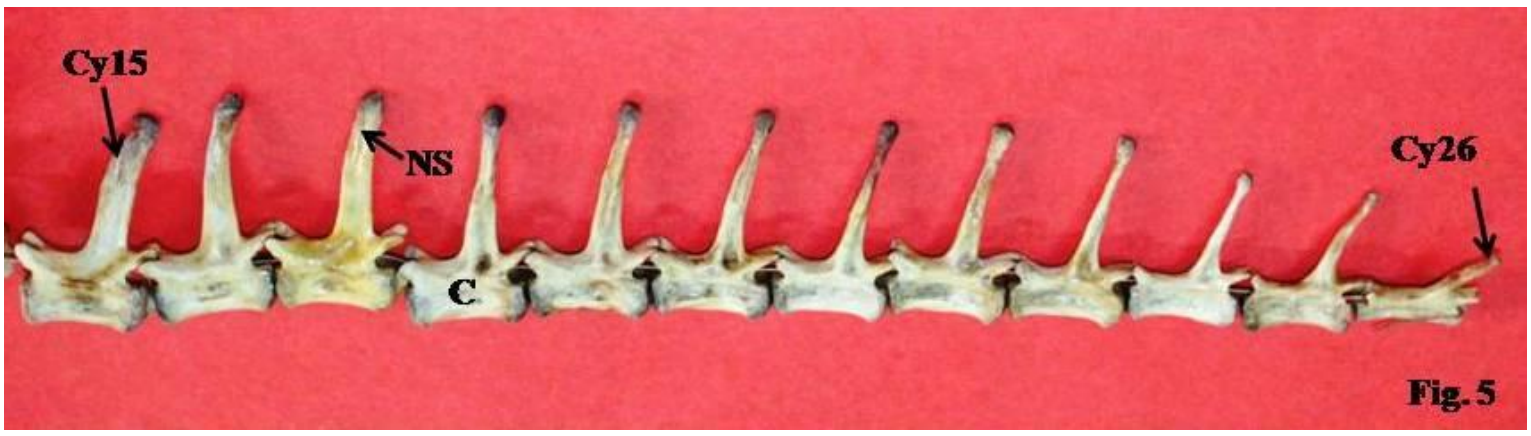


Fig.6 Photography was showing chevron bones

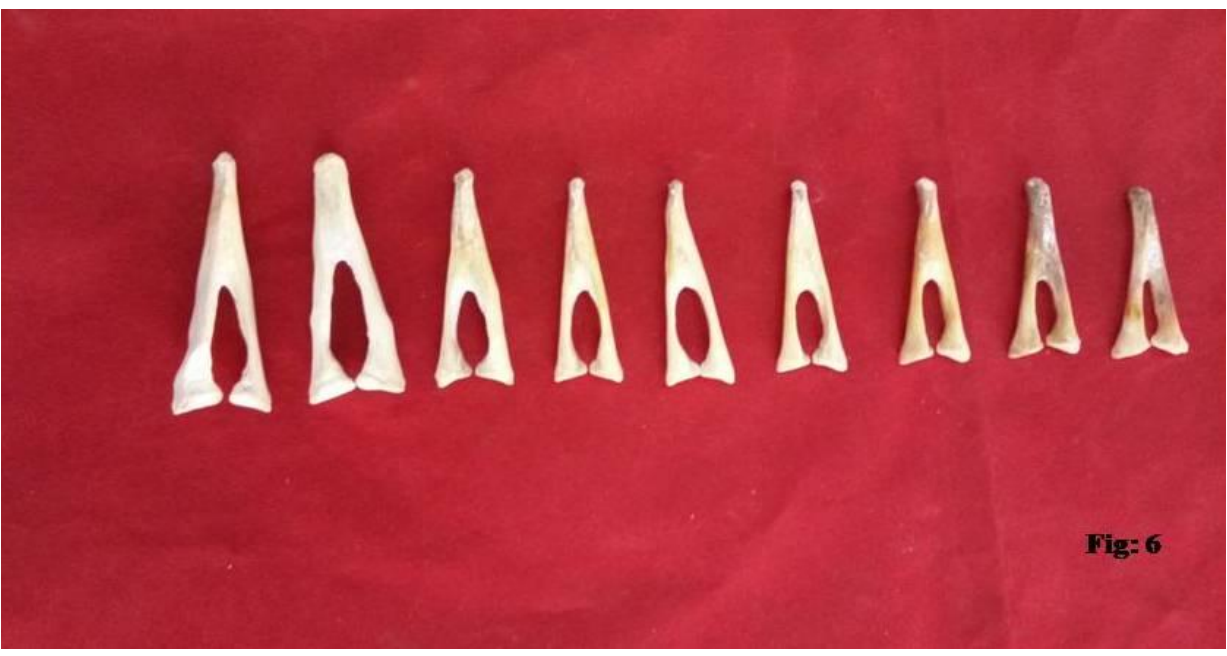

\section{Typical coccygeal vertebrae}

The centrum was cylindrical, rod-like structure around which the other processes were constructed. The mean length of the typical vertebrae gradually increased from $4.0 \mathrm{Cm}$ in $\mathrm{Cy}_{1}$ to 4.8.0 $\mathrm{Cm}$ in $\mathrm{Cy}_{14}$. Centrum of the first coccygeal vertebra was biconvex at either ends as reported by (Buscalioni and Sanz, 1990).

This indicates increasing shear stresses possibly associated with the acquisition of wide-gauge posture and perhaps also an increasing utilization of tripodal posture. Whereas, in remaining typical coccygeal, the centrum was procoelus type. This feature made the intercoccygeal joints stiffer in crocodiles as reported by Molnar et al., (2014) which helped in powerful stroke against prey and predators (Table 2).

The height of the neural spine increased gradually from $\mathrm{Cy}_{1}$ to $\mathrm{Cy}_{17}$ and showed cranial inclination. Inclination of the caudal series showed prominent caudal inclination. Whereas, the width of the neural spine decreased gradually from cranial to caudal series (Fig. 4). Transverse and vertical diameter of the vertebral ring decreased gradually in the present study.
The pre-zygapophyses were two in number, set wide apart and facing upwards. The articular faces were facing medially on either side and in front of the neural spine. Length and width of the pre-zygapophyses decreased gradually. The post-zygapophyses were situated behind the neural spine and faced downwards, articulated with the pre-zygapophyses of the succeeding coccygeal as in mammals (Dyce et al., 2010).

The transverse processes were two in number for each vertebra and projected laterally and showed backward inclination.

Length and width of the transverse processes decreased gradually in the present study (Table 2).

Nine numbers of $\mathrm{V}$-shaped chevron bones was observed in the posterio-ventral aspect of the cranial serious of the centrum (Fig. 6). The coccygeal vertebrae which provides virtually all of the thrust for swimming and it also provides propulsion while swimming in the water.

\section{Atypical coccygeal vertebrae}

In the present study, transverse processes were found to be absent from $\mathrm{Cy}_{15}$ to $\mathrm{Cy}_{26}$ onwards which made them atypical vertebrae (Fig. 5). All other processes were present, situated 
around the centrum. A longitudinal groove was observed in all the vertebrae on either side of the centrum.

All other processes of width and length were decreased gradually (Table 3 ). The atypical coccygeal vertebrae it will helpful for acceleration and very quick movements while swimming in the water.

\section{Acknowledgements}

The authors are thankful to the Professor and Head, Department of Veterinary Pathology, Madras Veterinary College for providing the Indian Marsh crocodile carcass which helped us to carry out this work.

\section{References}

Buscalioi, A.D and J. L. Sanz., 1990. The small crocodile Bernissartia fagesii from the lower cretaceous of galve (Teruel, Spain). Sciences De La Terre, 60: 129-150.

Da Silva, A and Lenin, J., 2010. "Mugger Crocodile Crocodylus palustris. Pp.94-98 in S.C. Manolis and C. Stevenson (eds.) Crocodiles Status Survey and Conservation Action Plan. 3rd edn., Crocodile Specialist Group: Darwin.

Dyce, K.M., W.O. Sack and C.J.G. Wensing, 2010. Text book of Veterinary Anatomy $4^{\text {th }}$ edn. Saunders Company.

Frey, E.F. and S.W. Salisbury, (2001). The kinematics of aquatic locomotion in Osteolaemus tetraspis Cope. In Crocodilian Biology and Evolution, Pp. 165-179. Baulkham Hills, NSW, Australia: Surrey Beatty \& Sons.

Fronimos, J.A. Wilson and T.K. Baumiller, 2016. Polarity of concavo-convex intervertebral joints in the necks and tails of sauropod dinosaurs. Paleobiology, 42(4): 624-642.
Girish Chandra, 2011. The Vertebral Column. http://www.iaszoology.com/tag/dr-girish chandra.

Hiremath, K.G., 2003. Recent advances in environmental sciences. Discovery Publishing House.

Johnston, S., J. Lever, R. McLeod, M. Oishi and S. Collins. 2014. Development of breeding techniques in the crocodile industry, pp: 33-40. Rural Industries Research and Development Corporation.

Molnar, J.L., S.E. Pierce, B. Anjan, S. Bhullar, A.H. Turner and J.R. Hutchinson, 2015. Morphological and functional changes in the vertebral column with increasing aquatic adaptation in crocodylomorphs. Royal Society Open Sciences. 2: 150439 (doi.Org/10.1098/rsos.150439).

Molnar. J.L., S.E. Pierce and J.R. Hutchinson. 2014. An experimental and morphometric test of the relationship between vertebral morphology and joint stiffness in Nile crocodiles (Crocodylus niloticus). The J. of Exp. Bio. 217: 758-768.

Onwuama, K.T., S.O. Salami, O. Ali, and J.O. Nzalak, 2012. Effect of different methods of bone preparation on the skeleton of the african giant pouched rat (Cricetomys gambianus). Int. J. Morphol., 30(2):425427.

Pierce S.E., J.A. Clack and J.R. Hutchinson. 2011. Comparative axial morphology in pinnipeds and its correlation with aquatic locomotory behaviour. J. Anat. 219: 502514.

Shapiro, L.J. 2007. Morphological and functional differentiation in the lumbar spine of lorisids and galagids. Am. J. Primatol. 69: 86-102.

Swinton, W.E., 1937. The Crocodile of Maransart (Dollosuchus dixoni). Pp: 2126.

\section{How to cite this article:}

Mayakkannan, T., T.A. Kannan, Geetha Ramesh and Venkatesan, S. 2018. Osteometrical Study of Sacrum and Coccygeal Vertebrae in a Marsh Crocodile (Crocodylus palustris). Int.J.Curr.Microbiol.App.Sci. 7(10): 1087-1094. doi: https://doi.org/10.20546/ijcmas.2018.710.119 